\title{
Pattern of Paediatric Rheumatic Diseases: An Experience in a Tertiary Care Hospital, Dhaka, Bangladesh
}

\author{
MOHAMMAD IMNUL ISLAM ${ }^{1}$, MANIK KUMAR TALUKDAR ${ }^{2}$, SHAHANAA RAHMAN ${ }^{3}$
}

\begin{abstract}
Background: The importance of Paediatric Rheumatic Diseases (PRDs) is increasing globally day by day. These diseases are considered as important chronic cause of childhood morbidity and disability. It is recognized that early recognition and diagnosis as well as timely intervention can improve the outcome of PRDs.
\end{abstract}

Objective: To estimate the pattern of PRDs and to compare the profile of JIA with other studies were done abroad.

\begin{abstract}
Method: Retrospective study was done in the paediatric rheumatology clinic and in patient department of Bangabandhu Sheikh Mujib Medical University (BSMMU) during the study period from July 2007-December 2012. All the patients fulfilling the ILAR classification criteria of Juvenile idiopathic arthritis (JIA), ACR classification criteria of systemic lupus erythematosus ( SLE), PReS-EULAR-PRINTO classification criteria of childhood vasculitis Bohan A, Peter JB Classification criteria for juvenile dermatomyositis (JDM) and preliminary criteria for the classification of systemic sclerosis (SS) were enrolled in this study.
\end{abstract}

Results: A total of 540 patients were enrolled. Highest number of patients had JIA (77\%), which was followed by SLE (10\%). Among childhood vasculitis, Henoch Shonlein purpura (HSP) was predominant (4.2\%) followed by Polyarteritis nodosa $(1.9 \%)$ and Kawasaki Disease (0.6\%). Juvenile dermatomiositis (JDM), systemic sclerosis (SS) and rheumatic fever was also found in 1.6\%, 1.3\% and $3 \%$ cases respectively. Polyarticular JIA was the commonest type (33\%) in this series, followed by oligoarthritis, systemic onset and enthesitis related arthritis (ERA).

Conclusion: JIA was the commonest among the paediatric rheumatic diseases followed by SLE and childhood vasculitis.

Keywords: PRDs, JIA, Vasculitis.

\section{Introduction:}

Rheumatic diseases in children are chronic intractable inflammatory diseases often with systemic life threatening complications. ${ }^{1}$ Paediatric rheumatic diseases (PRDs) are the commonest chronic cause of childhood morbidity and disability. Recent years have seen critical advances in understanding the nature of inflammation, the cells and the molecules that mediate it and the therapeutic possibilities of regulating

1. Assistant Professor, Department of pediatrics. Bangabandhu Sheikh Mujib Medical University, Dhaka.

2. Assistant Professor, Department of pediatrics. Bangabandhu Sheikh Mujib Medical University, Dhaka.

3. Professor, Department of pediatrics. Bangabandhu Sheikh Mujib Medical University, Dhaka.

Correspondence: Dr. Mohammad Imnul Islam, Assistant Professor, Department of Paediatrics, Bangabandhu Sheikh Mujib Medical University, Dhaka. M-01711393049, E-mail: imon27@gmail.com the aberrant immune response. One of the most important advances in paediatric rheumatology is the realization that varieties of rheumatic diseases affect children frequently and can impede normal growth and development. ${ }^{2}$ It is recognized that early recognition and diagnosis as well as timely intervention can improve the outcome of PRDs. Importance of PRDs is increasing globally day by day. But it had been difficult to establish the extent of PRDs in defined populations. ${ }^{3}$ Prevalence of JIA, which is the commonest rheumatological problem in children varies from 19.8 to 400 per 100000 children in different areas of the world. ${ }^{4}$ Prevalence of paediatric SLE ranges from 1.89 to 25.7 per 100000 which is the second most common PRDs. ${ }^{5}$ Vasculitis in children appears to have an incidence of about 50 cases per 100,000 
children per year. ${ }^{6}$ In Bangladesh no study on the incidence and prevalence of PRDs had been done. A small community based study found that prevalence of JIA was 60 per 100000 children in rural Bangladesh?. Objective of the present study was to estimate the pattern of PRDs in Bangladeshi children in a tertiary care hospital using the current classification criteria. This study was also designed to compare the clinical profile of JIA with other studies of abroad.

\section{Methods:}

It was a retrospective study carried out in the department of paediatrics, Bangabandhu Sheikh Mujib Medical University (BSMMU), Dhaka. Medical records from the paediatric rheumatology clinic and inpatient department of paediatrics from July 2007 to December 2012 were analyzed. All the patients fulfilling the ILAR classification criteria of Juvenile Idiopathic Arthritis (JIA), ${ }^{8}$ revised ACR classification criteria 1997 for SLE, ${ }^{9}$ EULAR-PReS classification criteria of childhood vasculitis, ${ }^{10}$ Bohan A, Peter JB classification criteria for $\mathrm{JDM}^{11}$ and preliminary criteria for the classification of Systemic Sclerosis (SS) ${ }^{12}$ were enrolled in this study. Data included demographic information, clinical and laboratory findings. These were processed and analyzed manually.

\section{Results:}

A total number of 540 patients were enrolled as PRDs during the study period. Table-I shows patient characteristics of this study. Among them $63.3 \%$ were male and $22.5 \%$ were female. Highest (49.1\%) number of patients was in the 11 to 16 years age group followed by $38.3 \%$ of patients in 6 to 10 years group. Among all PRDs highest number of patients had JIA (77\%) followed by SLE (10\%). Among childhood vasculitis, HSP was predominant (4.2\%) followed by polyarteritis nodosa (1.9\%) and Kawasaki disease (0.6\%). JDM, systemic sclerosis and acute rheumatic fever was found in $1.6 \%, 1.3 \%$ and $3 \%$ cases respectively.

Figure 1 shows the subtypes of JIA patients in this series. Polyarticular JIA was the commonest (38\%) followed by oligoarthritis, systemic onset and enthesitis related arthritis. Table II presents the comparison of the subtypes of JIA in this study with Indian and Canadian study. In Bangladeshi children, polyarticular JIA was highest (38\%) followed by persistent oligoarthritis (26\%). Systemic onset JIA (SoJIA) was found in $14 \%$ and enthesitis related arthritis (ERA) in $10 \%$ of JIA cases. Among polyarticular cases rheumatoid factor (RF) positive

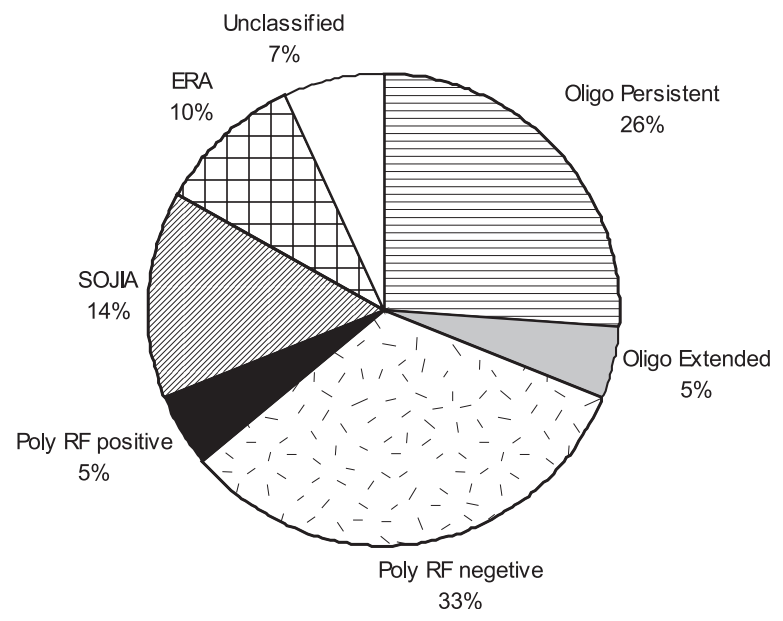

Fig.-1: Distribution of Subtypes of JIA in Bangladeshi children.

Table-I

Characteristics of patient profile $(n=540)$

\begin{tabular}{|c|c|c|c|c|c|}
\hline \multirow[t]{2}{*}{ Disease } & \multirow{2}{*}{$\begin{array}{l}\mathrm{N} \\
(\%)\end{array}$} & \multirow{2}{*}{$\begin{array}{c}\text { Sex } \\
(M / F)\end{array}$} & \multicolumn{3}{|c|}{ Age distribution at diagnosis } \\
\hline & & & $1-5 y r s$ & $6-10$ yrs & $11-16$ yrs \\
\hline JIA & $415(77)$ & $342 / 73$ & 66 & 151 & 198 \\
\hline SLE & $56(10.0)$ & $5 / 51$ & 02 & 15 & 39 \\
\hline HSP & $23(4.2)$ & $16 / 6$ & 03 & 15 & 05 \\
\hline PAN & $10(1.9)$ & $7 / 3$ & 1 & 07 & 02 \\
\hline JDM & $09(1.6)$ & $6 / 3$ & 00 & 03 & 06 \\
\hline SS & $07(1.3)$ & $5 / 2$ & 0 & 03 & 04 \\
\hline ARF & $16(3.0)$ & $14 / 2$ & 0 & 09 & 07 \\
\hline KD & $04(0.6)$ & $3 / 0$ & 02 & 02 & 0 \\
\hline$\overline{\text { Total }}$ & 540 & $398 / 142$ & 74 & 205 & 261 \\
\hline
\end{tabular}


Table II

Comparing subtypes of JIA in Bangladeshi children with Indian and Canadian study

\begin{tabular}{|c|c|c|c|c|c|c|c|c|c|}
\hline \multirow[t]{2}{*}{ Category } & \multicolumn{3}{|c|}{ Bangladeshi study, $\mathrm{n}=415$} & \multicolumn{3}{|c|}{ Indian study, $\mathrm{n}=235$} & \multicolumn{3}{|c|}{ Canadian study, $\mathrm{n}=69$} \\
\hline & $\begin{array}{c}\text { Frequency } \\
(\%)\end{array}$ & $\mathrm{M}: \mathrm{F}$ & $\begin{array}{c}\text { Onset age } \\
\text { yrs }\end{array}$ & $\begin{array}{l}\text { Frequency } \\
\text { (\%) }\end{array}$ & $M: F$ & $\begin{array}{c}\text { Onset age } \\
\text { yrs }\end{array}$ & $\begin{array}{c}\text { Frequency } \\
(\%)\end{array}$ & $\mathrm{M}: \mathrm{F}$ & $\begin{array}{c}\text { Onset age } \\
\text { yrs }\end{array}$ \\
\hline Oligo Persistent & 26.0 & $2.5: 1$ & 8.4 & 16.5 & $1: 1.4$ & 10 & 20.3 & $4: 10$ & 4.3 \\
\hline Oligo Extended & 5.1 & $2: 1$ & 9.3 & 4.3 & $1: 2$ & 9.75 & 13 & $2: 7$ & 4.4 \\
\hline Poly RF negative & 32.8 & 1.9:1 & 10.1 & 17.4 & $1: 1.6$ & 11.5 & 21.7 & $1: 2$ & 6.5 \\
\hline Poly RF positive & 5.0 & $1: 4$ & 12.2 & 11.5 & $1: 8$ & 13 & 5.8 & $0: 4$ & 10.5 \\
\hline SOJIA & 14.2 & $2.4: 1$ & 6.2 & 7.7 & $1.5: 1$ & 5.3 & 4.4 & $1: 2$ & 6.3 \\
\hline ERA & 10.0 & $8.75: 1$ & 14 & 35.3 & $1: 1$ & 13 & 11.6 & $3: 1$ & 11.8 \\
\hline Unclassified & 7.0 & $7: 1$ & 10.2 & 6.3 & 1:1 & 5.3 & 11.6 & 1:1 & 8.4 \\
\hline
\end{tabular}

cases were $5 \%$ and rest were RF negative. In Indian and Canadian children, polyarticular JIA cases were $28.9 \%$ and $27.5 \%$ respectively. Among them RF positive polyarticular JIA was found in $11.5 \%$ in Indian group and $5.8 \%$ in Canadian group. Systemic onset JIA was common in Indian children (7.7\%) compared to Canadian children (4.4\%). ERA was highest $(35.3 \%)$ in Indian children. Canadian study found that $33.3 \%$ children had oligoarthritis and $11.6 \%$ had unclassified category of JIA, which was highest among these three country studies.

When sex distribution was compared, male was predominant in Bangladeshi children in all the categories of JIA except RF positive Poly JIA. In contrary Canadian and Indian study found that female children were common in oligoarthritis and poly JIA groups. Males were affected more in systemic onset JIA in Indian study (1.5:1) than Canadian study (1:2). Males were the majority of ERA and unclassified categories in Bangladeshi JIA patients. But in these two categories of JIA, male and female children were equally distributed in Indian group. In Canadian study, male and female children were equal in unclassified type and male were predominant in ERA as like Bangladeshi and Indian patients.

\section{Discussion:}

Epidemiological studies for uncommon diseases like PRDs are sometimes difficult because of the rarity of the diseases and difficulties in diagnosis. Data are difficult to compare due to differences in diagnostic criteria, study designs and small sample size. In this retrospective study, information for quite a large number of uncommon diseases in children like JIA, SLE, HSP, systemic sclerosis, JDM and polyarteritis nodosa (PAN) were found.
During the five years of this retrograde study period, 540 patients were enrolled, among them 398 were male and 142 were female, male: female ratio being 2.8:1. It is well established that PRDs are female predominating diseases. ${ }^{13,14}$. In this study males were the main bulk of JIA patients. This might be due to the socio-cultural background where male children are given more importance and more care. Majority of children in this study presented at the age group of 11-16 years. All other studies done in our country in a hospital setting found similar results where male sex and late presentation with long duration of disease were common . ${ }^{15,16}$

A nationwide surveillance study on PRDs in Japan found $51.3 \%$ cases with JIA, $29 \%$ with SLE, $10.2 \%$ with JDM, $0.9 \%$ with SS and $0.6 \%$ cases with PAN. ${ }^{1}$ An USA based survey report on musculoskeletal problems in children found JIA as the largest group of their patient population (16\% of total cases). Other forms of childhood arthritis was $12 \%$, collagen vascular diseases was $9 \%$, and vasculitis was $3.3 \% .{ }^{17} \mathrm{~A}$ Canada based longitudinal study found that $31.6 \%$ of patient had JIA, 31\% had spondyloarthropathy, 34\% had collagen vascular disorder and $11 \%$ had others. ${ }^{18}$ It is to be noted that the Canadian study did not follow the ILAR classification critaeria. So, they reported spondylo-arthropathy separately. The result of the current study was consistent with different paediatric rheumatological disease profiles. In this study, JIA was the main bulk ( $77 \%)$ followed by SLE $(10 \%)$ and vasculitis (7\%). An Austrian study also found similar findings. ${ }^{19}$

In the present study it was found that poly JIA (RF negative) was the predominant type of JIA (33\%) 
followed by oligoarthritis (31\%), systemic onset (14\%), ERA (10\%), unclassified (7\%) and RF positive poly JIA (5\%). A recent Indian cohort found ERA as most predominant type of JIA (35.3\%) followed by poly JIA (29\%), oligoarthritis $(20.8 \%)$, systemic onset $(7.7 \%)$ and unclassified $(6.3 \%) .{ }^{20}$ Jennifer et al, in their study found that oligoarthritis was the commonest subtype $(50 \%)$ followed by poly JIA (30\%), systemic onset $(10 \%)$ and $\operatorname{ERA}(7 \%) .{ }^{21}$ The Canadian study also reflected similar findings showing oligoarthritis type as the commonest (33.3\%) followed by poly JIA (27\%), ERA, unclassified and systemic onset. 20

Male children were found as the main bulk of JIA cases both in Bangladeshi and Indian studies. But in Canadian and Spanish studies female children formed the major bulk. The age of presentation in the Bangladeshi and Indian cohort were found comparatively higher in all the subtypes of JIA except systemic onset. It is found that Asian children with JIA were different from Caucasian children by relative male predominance, older age of onset and different subtypes of JIA. ${ }^{22}$

\section{Conclusion:}

JIA was the commonest problem among the paediatric rheumatic diseases followed by SLE and childhood vasculitis. Most of the patients came to the paediatric rheumatology clinic quite late. Early diagnosis and effective management of these children is essential so that they can lead a normal or near normal life. So, raising awareness and dissemination of knowledge about PRDs among medical professionals can ensure early referral which would help better care for children with rheumatic diseases.

\section{References:}

1. Fujikawa S, Okuni M. A nationwide surveillance study of rheumatic diseases among Japanese children. Acta Paediatrica Japonica 1997; 39: 242-44.

2. Rosenberg AM. Advances in Paediatric rheumatology . Can.Fam.physician 1990; 36:531-37.

3. Cassidy J T, Petty R E. Introduction to the study of the Rheumatic disease in children. In: Cassidy J T, Petty R E, Laxer R M, Lindsley C B, editors. Textbook of paediatric rheumatology. $5^{\text {th }}$ edn. Elesvier Saunders; Philadelphia : 2005.p 2-7.

4. Manners PJ, Bower C. Worldwide prevalence of Juvenile Arthritis-Why does it vary so much? J Rheumatol 2002; 29:1520-30.
5. Pineles D, Valente A, Warren B, Peterson MGE, Lehman TJA, Moorthy LN. Worldwide incidence and prevalence of pediatric onset systemic lupus erythematosus. Lupus 2011; 0: 1-6.

6. Khubchandani R P, Viswanathan V. Paediatric vasculitides : A generelists approach. Indian J Pediatr 2010; 77:1165-71.

7. Azam S, Dipti T, Rahman S. Prevalence and clinical pattern of juvenile idiopathic arthritis in a semi urban area of Bangladesh. International Journal of Rheumatic Disease 2012; 15:116-20.

8. Petty RE, Southwood TR, Manners P, Baum J, Glass DN, Goldenberg J, et al. International League of Associations for rheumatology classification of juvenile idiopathic arthritis: $2^{\text {nd }}$ revision, Edmonton, 2001. J Rheumatol 2004; 31:390-2.

9. Hochberg MC. Updating the American College of Rheumatology revised criteria for the classification of systemic lupus erythematosus. Arthritis Rheum 1997; 40: 1725.

10. Ozen S, Ruperto N, Dillon M J, Bagga A, Barron K, Davin JC et al. EULAR-PReS endorsed consensus classification criteria for childhood vasculitides. Ann Rheum Dis 2006; 65; 936-41.

11. Rider GL, Lindsley CB, Cassidy JT. Juvenile Dermatomyositis. In: Cassidy JT, Petty RE, Lindsley CB, Ronald ML editors. Textbook of paediatric rheumatology, $6^{\text {th }}$ edition. Saunders Elsevier; Philladelphia: 2011. p. 375-413.

12. Zullian F, Cassidy JT. The systemic sclerodermas and related disorders. In: Cassidy JT, Petty RE, Lindsley CB, Ronald ML editors. Textbook of paediatric rheumatology, $6^{\text {th }}$ edition. Saunders Elsevier; Philladelphia: 2011. p. 41447.

13. Cassidy JT, Petty R E. Chronic arthritis in childhood In: Cassidy J T, Petty R E, Laxer R $M$, Lindsley $C B$, editors. Textbook of paediatric rheumatology. $5^{\text {th }}$ edn. Elesevier Saunders; Philadelphia : 2005.p 211-48.

14. Silverman E, Eddy A. Systemic Lupus Erythematosus In: Cassidy J T, Petty R E, Laxer $R$ M, Lindsley C B, editors. Textbook of paediatric rheumatology. $5^{\text {th }}$ edn. Elesevier Sunders; Philadelphia: 2005.p 315-60. 
15. Rahman SA, Islam M I, Hossain M, Talukder M $\mathrm{K}$. Clinical presentation of Juvenile Idiopathic Arthritis in Bangladesh: experience from a tertiary hospital. International Journal of Rheumatic Disease 2008; 11:50-54.

16. Islam M I, Hossain M, Rahman SA. Performance of preliminary definition of improvement in Juvenile Idiopathic Arthritis patients treated with methotrexate: experience of Bangladesh. International Journal of Rheumatic Disease 2008; 11:241-45.

17. Bowyer S, Roettcher P. Pediatric rheumatology clinic populations in the United States: results of a 3 year survey. Pediatric Rheumatology Database Research Group. J Rheumatol 1996; 23:1968-74.

18. Rosenberg AM. Longitudinal analysis of a pediatric rheumatology clinic population. J Rheumatol 1990; 32: 1992-2001.
19. Huemer C, Huemar M, Dorner T, Falger J, Schaccherl $\mathrm{H}$, Bernecker $\mathrm{M}$ et al. Incidence of Pediatric Rheumatic Diseases in a regional population in Austria. The Journal of Rheumatology 2001; 28:2116-19.

20. Kunjir V, Venugopalan A, Chopra A. Profile of Indian Patients with Juvenile Onset Chronic Inflammatory Joint Disease Using the ILAR classification criteria for JIA: A community based Cohort study. The Journal of Rheumatology 2010; 37: 1756-62.

21. Jennifer E W, Norman T I. Juvenile Idiopathic Arthritis. Pediatric clinic of North America 2005;52: 413-442.

22. Huang J L, Yao T C, See L C. Prevalence of systemic lupus erythematosus and juvenile chronic arthritis in a Chinese population: A nation wide prospective population based study in Taiwan. Clinical and Experimental rheumatology 2004; 22:726-780. 